\title{
Prenatal counseling for myelomeningocele in the era of fetal surgery: a shared decision-making approach
}

\author{
Vijay M. Ravindra, MD, MSPH, ${ }^{1}$ Guillermo Aldave, MD, PhD, ${ }^{1}$ Howard L. Weiner, MD, ${ }^{1}$ \\ Timothy Lee, MD, ${ }^{3}$ Michael A. Belfort, MD, PhD, ${ }^{1,2}$ Magdelena Sanz-Cortes, MD, ${ }^{2}$ \\ Jimmy Espinoza, MD, ${ }^{2}$ Alireza A. Shamshirsaz, MD, PhD, ${ }^{2}$ Ahmed A. Nassr, MD, ${ }^{2}$ and \\ William E. Whitehead, MD ${ }^{1,2}$
}

1Division of Pediatric Neurosurgery, ${ }^{2}$ Department of Obstetrics, and ${ }^{3}$ Division of Pediatric Surgery, Baylor College of Medicine, Houston, Texas

\begin{abstract}
OBJECTIVE The Management of Myelomeningocele Study demonstrated that fetal surgery, as compared to postnatal repair, decreases the rate of hydrocephalus and improves expected motor function. However, fetal surgery is associated with significant maternal and neonatal risks including uterine wall dehiscence, prematurity, and fetal or neonatal death. The goal of this study was to provide information about counseling expectant mothers regarding myelomeningocele in the era of fetal surgery.
\end{abstract}

METHODS The authors conducted an extensive review of topics pertinent to counseling in the setting of myelomeningocele and introduce a new model for shared decision-making to aid practitioners during counseling.

RESULTS Expectant mothers must decide in a timely manner among several potential options, namely termination of pregnancy, postnatal surgery, or fetal surgery. Multiple factors influence the decision, including maternal health, fetal heath, financial resources, social support, risk aversion, access to care, family planning, and values. In many cases, it is a difficult decision that benefits from the guidance of a pediatric neurosurgeon.

CONCLUSIONS The authors review critical issues of prenatal counseling for myelomeningocele and discuss the process of shared decision-making as a framework to aid expectant mothers in choosing the treatment option best for them. https://thejns.org/doi/abs/10.3171/2019.12.PEDS19449

KEYWORDS fetal surgery; spina bifida; myelomeningocele; prenatal counseling; shared decision-making; congenital

$\mathrm{H}$ ISTORICALLY, fetal surgery has been limited to use for severe conditions that will result in fetal or neonatal death. All procedural risks to mother and fetus are considered in the setting of almost-certain death without intervention. Recently, the Management of Myelomeningocele Study (MOMS) demonstrated benefits from fetal surgery in children with myelomeningocele (MMC). Since MMC is not uniformly lethal, these benefits are more difficult to balance against the risks of intervention. ${ }^{1}$ The option for fetal surgery is also limited by time because the surgery must be performed before 26

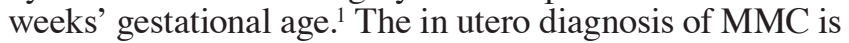
usually made between 16 and 18 weeks. This gives expectant mothers 8-10 weeks to receive counseling, decide on treatment, and arrange fetal surgery if they so choose. The addition of fetal surgery as a treatment option, one of only a few neurosurgical procedures supported by a random- ized trial, can significantly complicate prenatal counseling for MMC.

At its core, the idea of shared decision-making means that patients have the opportunity to participate in decisions about their own care (as opposed to clinicians making decisions on behalf of patients). ${ }^{33}$ The approach is based on the principle of individual self-determination. It accepts that people have different needs, values, and risk tolerances and that individuals should make decisions based on what is most important to them.

In this paper, we describe how to use the shared decision-making approach in prenatal counseling for MMC.

\section{Key Background Information for Prenatal Counseling}

The first step, a key step, to the shared decision-making

ABBREVIATIONS CM-II = Chiari malformation type II; ETVICPC = endoscopic third ventriculostomy with choroid plexus cauterization; MMC = myelomeningocele; $M O M S=$ Management of Myelomeningocele Study.

SUBMITTED September 1, 2019. ACCEPTED December 16, 2019.

INCLUDE WHEN CITING Published online February 28, 2020; DOI: 10.3171/2019.12.PEDS19449. 
model is providing high-quality information about the diagnosis and prognosis. Equally important is finding out what the patient already knows and ensuring that it is correct. Only an informed patient can make assessments about what is important to her and her child.

The sections below review key concepts that expectant mothers should understand (Table 1). This list is comprehensive, but additional topics may need to be discussed based on specific patient circumstances.

\section{Explaining the Diagnosis}

In general, the terms "spina bifida" and "myelomeningocele" need to be defined for expectant mothers. Women should understand that MMC occurs when the spinal cord fails to separate from the skin during gestation, resulting in constant leakage of spinal fluid through the defect that has consequences on the developing brain and leads to many of the comorbidities. ${ }^{36}$

Most cases are sporadic and multifactorial in origin (90\%); the remaining cases can be tied to chromosomal abnormalities or singe-gene disorders..$^{20,52}$ The known associated genetic disorders include trisomy 13 and 18; Börjeson-Forssman-Lehman, Meckel, and PHAVER syndromes; and X-linked neural tube defects. Other risk factors include family history and maternal medications (i.e., valproate, carbamazepine), obesity, pregestational diabetes, or febrile illness early in pregnancy.

It is valuable to mention during the counseling session that future pregnancies also carry an increased risk of spina bifida (5\%) and that high-dose folate supplementation can lower that risk if started 3 months before conception. ${ }^{39}$

\section{Survival}

Unless there are severe congenital anomalies, children with MMC will likely survive. Historically, mortality rates within the 1 st year were $21 \%-37.5 \% ;{ }^{24,29}$ however, in a more recent series of 101 children born with MMC, there was just 1 death in the 1 st year. ${ }^{51}$ The MOMS demonstrated a mortality rate of $3 \%$ in the 1 st year. ${ }^{1}$ Ventriculitis and shunt-related complications were considered the prime causes of death during infancy; however, brainstem dysfunction (due to Chiari malformation type II [CM-II]) leading to respiratory impairment and swallowing dysfunction causes most early deaths. ${ }^{7,50}$ As patients age, mortality remains significant $-25 \%$ overall at 25 years, ${ }^{7}$ with an estimated mean survival of 30 years. ${ }^{13,24}$ Renal complications are the most common cause of death for adult patients. ${ }^{48,62}$ No long-term survival data exist for patients who have undergone fetal closure.

\section{Hydrocephalus}

Hydrocephalus is the most common and resource-intensive comorbidity of MMC. Shunting rates have historically been $52 \%-90 \%$ after postnatal closure; $;, 11,44,49$ in the MOMS, the rates were $40 \%$ for the fetal surgery cohort and $82 \%$ for the postnatal closure cohort. ${ }^{1}$ Treatment criteria during the MOMS included at least 2 of the following: increase in the occipitofrontal circumference defined as crossing percentiles, bulging fontanelle, increasing hydrocephalus on consecutive imaging studies, or head
TABLE 1. Key concepts for prenatal counseling in shared decision-making model

\begin{tabular}{|c|c|}
\hline Defining MMC & $\begin{array}{l}\text { Spinal cord fails to separate from skin during } \\
\text { gestation, resulting in constant leakage of } \\
\text { spinal fluid through defect }\end{array}$ \\
\hline Survival & $\begin{array}{c}\text { Mean survival } 30 \text { yrs; }{ }^{13,24} 1 \text {-yr mortality: } 1 \%-3 \% \\
\text { postnatal surgery, }{ }^{51} 3 \%-6 \% \text { fetal surgery }{ }^{1}\end{array}$ \\
\hline Hydrocephalus & $\begin{array}{l}50 \%-90 \% \text { in postnatal repairs: }{ }^{7,11,44,49} 40 \% \text { in } \\
\text { prenatal repairs; }{ }^{-1} \text { ETV/CPC successful in } \\
55 \%-72 \% 45,60\end{array}$ \\
\hline Paraplegia & $\begin{array}{l}\text { Ambulation directly related to lesion level; most } \\
\text { patients w/ low lumbar \& sacral lesions am- } \\
\text { bulate independently regardless of treatment } \\
\text { choice:1,46 fetal surgery preserves existing } \\
\text { motor function }{ }^{1}\end{array}$ \\
\hline $\begin{array}{l}\text { Neurogenic bowel/ } \\
\text { bladder }\end{array}$ & $\begin{array}{l}\text { Majority of patients affected; social continence } \\
\text { achievable in }>80 \%,{ }^{7,26,49} \text { early results of fetal } \\
\text { surgery do not show significant improve- } \\
\text { ments (long-term studies needed) }{ }^{8}\end{array}$ \\
\hline Scoliosis & $\begin{array}{l}\text { Effect of fetal surgery on incidence of scoliosis } \\
\text { unknown }\end{array}$ \\
\hline CM-II crisis & $\begin{array}{l}3 \%-8 \% \text { of MMC patients:50 caused by severe } \\
\text { brainstem dysplasia; not prevented by fetal } \\
\text { surgery }\end{array}$ \\
\hline $\begin{array}{l}\text { Tethered cord \& spi- } \\
\text { nal inclusion cysts }\end{array}$ & $\begin{array}{l}\text { Uncommon, but rates may be higher after fetal } \\
\text { surgery }{ }^{1,12}\end{array}$ \\
\hline Cognitive outcomes & $\begin{array}{l}\text { Majority have average to above-average intel- } \\
\text { ligence }(70 \%) ; 4050 \% \text { of adult patients live in- } \\
\text { dependently \& } 25 \%-38 \% \text { are employed; } 24,56 \\
\text { fetal surgery has no known adverse or } \\
\text { beneficial effects (early results) }{ }^{1}\end{array}$ \\
\hline
\end{tabular}

circumference $>95$ th percentile. Additional independent criteria included marked syringomyelia with ventriculomegaly, ventriculomegaly and symptoms of CM (stridor, swallowing difficulties, apnea, bradycardia), or persistent cerebrospinal fluid leakage from the MMC wound or bulging at the repair site. These criteria ${ }^{41,55}$ were used in an attempt to standardize shunt placement for MMC, but there was still much variability. Placement of a shunt imposes significant morbidity, and shunt-related complications can be detrimental to cognitive outcome ${ }^{3}$ and longterm survival. ${ }^{13,23,40,53,54}$ Shunt revision rates can be high in the MMC population; ${ }^{7,49}$ in one study, ${ }^{10} 46 \%$ of patients with shunts required shunt revision in the first postoperative year (75\% from mechanical failure). Shunt infection rates can be higher for patients with MMC than for other hydrocephalus groups..$^{53}$

Since the MOMS, there has been a significant change in the management of hydrocephalus. Endoscopic third ventriculostomy with choroid plexus cauterization (ETV/ CPC) has become another treatment option for hydrocephalus. ${ }^{27,59,60}$ It is an option regardless of whether or not the child had prenatal surgery. The long-term cognitive effects of this procedure are not clear, and there is a higher failure rate in the first 6 months than after shunt placement; however, a successful procedure avoids the lifelong morbidity associated with an implant, and ventriculitis 
rates are lower. Success rates in MMC patients range from $55 \%$ to $72 \% .{ }^{45,60}$ The role of ETV/CPC will undoubtedly be elucidated through future comparative studies.

\section{Paraplegia and Ambulation}

In the absence of severe developmental delay, which can occur in approximately $13 \%$ of children with MMC, independent mobility is directly related to the lesion level. For lower lumbar and sacral lesions, ambulation occurs in almost all cases. For lesions above L2, the loss of quadriceps and iliopsoas muscle function means that independent ambulation is not likely and wheelchair dependence is expected ${ }^{34,46}$ Early intervention from physical therapy and orthopedics is encouraged to achieve the best motor function possible. As patients age, they become less ambulatory likely because of weight gain, progressive lower-extremity deformity, and pulmonary compromise. ${ }^{9}$ One study found that $30 \%$ of patients were ambulatory at the 30-year follow-up (88\% for lesions below L4), ${ }^{40}$ and another reported that $52 \%$ of adult patients walked independently and $21 \%$ were ambulatory with aids; all patients with sacral-level MMC remained ambulatory. ${ }^{46}$ In the MOMS, children in the fetal surgery group were more likely than those in the postnatal surgery group to be able to walk without orthotics or devices ( $42 \%$ vs $21 \%$, respectively, $\mathrm{p}=0.01)$. On both the Bayley and Peabody motor scales, motor function was superior in the prenatal surgery group even though children in that group had more severe anatomical lesions. Long-term results regarding ambulation and functionality remain to be seen. ${ }^{1}$

\section{Neurogenic Bladder and Bowel}

Urinary incontinence and damage to the upper urinary tract are common features of MMC. Kidney damage from reflux and recurrent urinary tract infections are early sources of morbidity and subsequent mortality. ${ }^{15}$ Improved management, including intermittent catheterization, anticholinergic drugs, and aggressive management of constipation, has significantly improved the urological prognosis. Social continence (bowel and bladder) can now be achieved in more than $80 \%$ of children.,26,49 Surgical procedures to increase bladder capacity are also used in this population. Macedo et al. ${ }^{31}$ found little benefit to fetal surgery, with a high incidence of abnormal bladder patterns, and early analysis of subjects in the MOMS showed no significant benefit from fetal surgery in terms of bladder outcomes. ${ }^{8}$ Longer-term follow-up is needed, but fetal surgery does not appear to prevent neurogenic bowel and bladder.

\section{Scoliosis}

MMC is a major cause of neuromuscular scoliosis, and spinal deformity is common. The multifactorial causes in MMC include spinal bony anomaly, neuromuscular imbalance, and spasticity associated with pelvic and hip deformity. ${ }^{14}$ The severity of scoliosis and the need for surgical intervention are related to neurological level, functional status, pulmonary compromise related to curvature, skin breakdown, sitting balance, and curve progression. There is no known effect of fetal surgery on the rates of neuromuscular scoliosis.

\section{CM-II and Chiari Crisis}

CM-II is present in almost all MMCs and can be symptomatic in up to $25 \%-33 \%$ of cases. ${ }^{62,63}$ Characterized by hindbrain herniation, the CM-II consists of multiple anomalies of the brain brought on by decompression of fluid in the vesicles through the MMC defect. The most recognized characteristic is growth of the vermis through the foramen magnum into the cervical canal, but other features include caudal displacement of the brainstem, tectal beaking, aqueductal stenosis, polymicrogyria, absence of the corpus callosum, brainstem dysplasias, and enlargement of the massa intermedia. Fetal surgery significantly reduces hindbrain herniation at 1 year, ${ }^{1}$ but other features are variable and not reversible with fetal surgery. McLone and Dias ${ }^{35}$ have argued that symptomatic CM-II with brainstem dysplasia is the major determinant of quality of life for children with MMC. Infants manifest central apnea and lower cranial nerve deficits or dysfunction, whereas older children present with neck pain, headache, and sensory or motor disturbances of the limbs. Apnea, stridor in the setting of vocal cord paralysis, and difficulty swallowing may constitute a CM-II crisis, with up to $15 \%$ of symptomatic patients dying by the 3rd year. ${ }^{50}$ Hydrocephalus can drive worsening symptoms and is always addressed before considering surgical decompression, tracheostomy, and gastric tube placement. The rates of severe brainstem dysplasia leading to CM-II crisis are not known to be influenced by fetal surgery; however, in the MOMS, 1 child in the prenatal surgery group required CM-II decompression versus 4 in the postnatal surgery group $(\mathrm{p}=$ -0.37). Further detailed attention to specific symptoms when comparing techniques will be important in future investigations.

\section{Tethered Cord and Spinal Inclusion Cysts}

After the initial surgery to untether the neural placode from the skin, the placode remains low in the spinal canal and retethers to the dura mater through the formation of scar tissue. Serial lumbar spine MRI scans will continue to show elongation of the spinal cord to the level of the spina bifida defect, and the spinal cord will always appear radiographically tethered. As axial growth occurs, traction exerted on the spinal cord and nerve roots can lead to mechanical stretch, ischemic injury, and subsequent neurological deterioration. ${ }^{63}$ Additional symptoms can include urological dysfunction and foot and spinal deformity. Early recognition of this process and timely surgical intervention to untether the spinal cord can lead to significant improvement. ${ }^{22}$ Early results from the MOMS have suggested a trend toward higher rates of symptomatic tethered cord after fetal intervention $(8 \%$ vs $1 \%$, p < $0.06){ }^{1}$ This finding may be attributable to differences in the closure technique, to better motor function in the fetal intervention group that makes them more sensitive to tethering, or to both.

Epidermoid and dermoid inclusion cysts can occur after closure in both fetal and postnatal surgery because of retention of ectodermal elements in the spinal canal. Serial imaging studies can demonstrate this, but children often present with neurological worsening and signs compatible with spinal cord tethering. Early reports of fetal 
MMC closure before the MOMS have suggested higher rates of inclusion cysts after fetal surgery, but this finding was not seen in the MOMS.,12

\section{Cognitive Outcome}

Although cognitive dysfunction depends on many factors, approximately $70 \%$ of patients with MMC will have an IQ $\geq 80 . .^{40}$ According to one study, approximately half of adult patients with MMC were living independently, while the remainder required supervision or were completely dependent on care. ${ }^{24}$ Hunt concluded that only $25 \%$ of adult patients with MMC were capable of open employment. ${ }^{24}$ However, a more recent study showed that $38 \%$ of adults were actively employed. ${ }^{56}$ The MOMS reported no significant difference in Bayley's mental development index at 30 months between prenatal and postnatal surgery groups. ${ }^{1}$ Long-term cognitive outcomes are still being evaluated in the fetal surgery patients.

\section{Spina Bifida Clinic}

Parents should understand that although most major comorbidities of MMC have treatments, there is no cure for MMC. To achieve optimal outcomes, long-term monitoring and coordination of care among specialists are necessary and can be achieved through a multidisciplinary spina bifida clinic. Discussion with the spina bifida clinic helps families develop an idea of the care involved and how each condition will be monitored by neurosurgery, urology, physical medicine and rehabilitation, pediatrics, and orthopedic surgery.

\section{Discussion of Treatment Options in a Shared Decision-Making Model}

The US Preventive Services Task Force defines shared decision-making as the "process in which patients are involved as active partners with the clinician in clarifying acceptable medical options and choosing a preferred course of clinical care." ${ }^{\prime 7}$ As is the case in fetal MMC repair, shared decision-making is particularly important given that some patients may benefit from the intervention and some may not. ${ }^{18,57}$ For the shared decision-making to be successful, expectant mothers should understand that multiple legitimate treatment options exist and that there is not one best treatment. Women should make decisions based on informed preferences unique to their situation.

\section{Pregnancy Termination}

Laws regarding pregnancy termination vary among states. Most expectant mothers have decided not to terminate before seeing a neurosurgeon, although this is not always true. In such cases, it can be valuable to gain the perspective of a pediatric neurosurgeon regarding treatments and quality of life issues.

\section{Postnatal Repair}

Postnatal repair is the safest treatment option for mother and baby; it is associated with the lowest mortality and complications. ${ }^{1}$

Postnatal closure usually occurs within the first 72 hours of life; ${ }^{1}$ however, closure within $24-48$ hours is commonly performed. Prenatal counseling by the neurosurgeon is a good opportunity to discuss the goals of surgery, the surgical technique, the risks, and the recovery. The goals of surgery to obtain a watertight seal, prevent infection, and protect nerves from external trauma should be emphasized so parents are aware that the surgery does not restore function.

For postnatal repair, most obstetricians recommend a cesarean section to avoid trauma to the exposed neural tube. ${ }^{30}$ Pregnancy complications and preterm delivery are rare; there were no cases of extreme prematurity in the MOMS postnatal group. ${ }^{1}$

\section{Introducing the Option of Fetal Surgery During Counseling}

\section{Screening Patients for Fetal Surgery}

Initial screening of patients for fetal surgery at most centers uses the MOMS criteria. ${ }^{1}$ Noncandidates can be advised early that fetal surgery is not an option. The fetal MMC surgery criteria include both maternal and fetal characteristics (Table 2). If both mother and fetus meet the criteria for fetal surgery, then a detailed screening process is undertaken, which includes fetal echocardiogram and possibly MRI. The fetal echocardiogram must be normal to justify the risk of fetal surgery. The MRI helps with the planning for surgery by characterizing the lesion, uterine anatomy, and placental location.

\section{A Multidisciplinary Approach}

When considering fetal surgery, practitioners often place the highest level of importance on neonatal benefits, followed by the risk of maternal complications. Even in the setting of fetal surgery, there are differences in attitude toward fetal intervention. Antiel et al. ${ }^{2}$ identified 4 attitudes toward fetal intervention: fetocentric, risk sensitive, maternal autonomy, and family impact and social support. Neonatologists were more likely to be in the fetocentric group, whereas surgeons were more likely to be in the risk-sensitive group, and maternal-fetal medicine physicians made up the largest percentage of the group focused on family impact and social support. Thus, a nonbiased, multidisciplinary approach should be taken toward the potential for fetal surgery and include input from maternal-fetal medicine specialists, neurosurgeons, anesthesiologists, pediatric surgeons, neonatologists, and social workers.

\section{Details of Fetal Repair to Review With Candidates}

There are several myths about fetal MMC repair, perhaps attributable to the popularization of information through the media and social media, that must be addressed early in the counseling process (Table 3). One common misconception is that "without fetal surgery, my child has no chance to walk." As discussed above, the ability to ambulate independently is related to the lesion level, with patients harboring lesions below L4 having greater success. Fetal surgery has improved motor outcomes at 30 months and increased the percentage of ambulatory patients, ${ }^{1}$ but the notion that there is no chance of ambulation 
TABLE 2. Fetal surgery screening criteria in MMC

\begin{tabular}{|c|c|c|c|}
\hline \multicolumn{2}{|c|}{ Inclusion Criteria } & \multicolumn{2}{|c|}{ Exclusion Criteria } \\
\hline Fetal & Maternal & Fetal & Maternal \\
\hline Level of lesion btwn T1 \& S1 & Singleton pregnancy & $\begin{array}{l}\text { Spinal kyphosis }>30 \% \text { gibbus } \\
\text { deformity }\end{array}$ & Placenta previa or placental abruption \\
\hline Presence of hindbrain herniation & & & Short cervix $(<2 \mathrm{~cm})$ \\
\hline Defect not thought to be skin covered & & & $\begin{array}{l}\text { Pregestational insulin-dependent diabetes } \\
\text { mellitus }\end{array}$ \\
\hline Normal karyotype & & & History of incompetent cervix \\
\hline Gestational age <26 wks & & & Obesity $\left(\mathrm{BMI}>35 \mathrm{~kg} / \mathrm{m}^{2}\right)$ \\
\hline \multirow[t]{7}{*}{ No other major fetal anomaly } & & & $\begin{array}{l}\text { Previous spontaneous singleton delivery } \\
\text { before } 37 \text { wks }\end{array}$ \\
\hline & & & $\begin{array}{l}\text { Maternal-fetal Rh isoimmunization, Kell } \\
\text { sensitization, or history of neonatal } \\
\text { alloimmune thrombocytopenia }\end{array}$ \\
\hline & & & HIV or hepatitis B or C \\
\hline & & & $\begin{array}{l}\text { History of neonatal alloimmune thrombo- } \\
\text { cytopenia }\end{array}$ \\
\hline & & & Uterine anomaly such as large fibroids \\
\hline & & & No support person \\
\hline & & & Hypertension \\
\hline
\end{tabular}

$\mathrm{Rh}=$ Rhesus .

without fetal surgery is false. Another misconception is that "fetal surgery is a cure for spina bifida." There is no cure for spina bifida, but fetal surgery can help improve motor function and some of the outcomes related to hydrocephalus. A further related misconception is that "fetal surgery is the new standard of care"; however, the standard of care remains postnatal closure, which has the lowest risk of fetal death and maternal morbidity. Fetal surgery is a new treatment option but has not replaced postnatal closure.

\section{Benefits of Fetal MMC Repair}

The benefits of fetal MMC repair include a lower risk of hydrocephalus and improved lower-extremity motor outcomes. ${ }^{1}$ In the MOMS, the risk of hydrocephalus was reduced by $50 \%$ in the fetal surgery group (40\% required a shunt vs $80 \%$ in the postnatal repair group). Lowerextremity motor function was also improved, with $40 \%$ of fetal surgery patients ambulating independently versus $20 \%$ in the postnatal repair group. These are clinically significant improvements that justify the option of fetal surgery, but expectant mothers should also be told that not every patient avoids hydrocephalus or achieves independent ambulation.

Data obtained during the prenatal evaluation can iden- tify patients most likely to benefit from fetal intervention and should be presented to every expectant mother considering it. Post hoc evaluation of the MOMS revealed that ventricular size in the second trimester predicts the rate of hydrocephalus in the fetal surgery group, with smaller ventricles $(<10 \mathrm{~mm}$ across the atrium of the lateral ventricle) yielding the lowest risk (20\%) and larger ventricles (>15 mm) yielding the highest $(79 \%) .{ }^{55}$ The risk of hydrocephalus with large ventricles is almost as high as the risk in the postnatal surgery group; therefore, in these cases, it makes little sense to choose fetal surgery to avoid hydrocephalus.

Lower-extremity motor function can be determined by fetal ultrasonography. ${ }^{32}$ Ultrasound can be used to determine the degree of movement and identify the presence of clubbed feet. When the fetus already has significant weakness of the lower extremities with clubbing of the feet, fetal intervention will not reverse the paralysis. However, when lower-extremity function is normal, without clubbed feet, especially when the lesion is high, fetal surgery can protect the exposed nerves from trauma and the toxicity of the amniotic fluid, thus preserving motor function.

The best candidates for fetal surgery meet the MOMS criteria, have small ventricles, and have good lowerextremity motor function with a high lesion level. The

TABLE 3. Common misconceptions about fetal surgery

\begin{tabular}{|c|c|}
\hline Misconception & Reality \\
\hline "Without fetal surgery, my child has no chance to walk" & Ability to walk depends on lesion level \\
\hline "Fetal surgery is a cure for spina bifida" & No cure; this is chronic, lifelong condition \\
\hline "Fetal surgery is the new standard of care" & Postnatal repair is still standard of care; fetal surgery is new treatment option \\
\hline
\end{tabular}




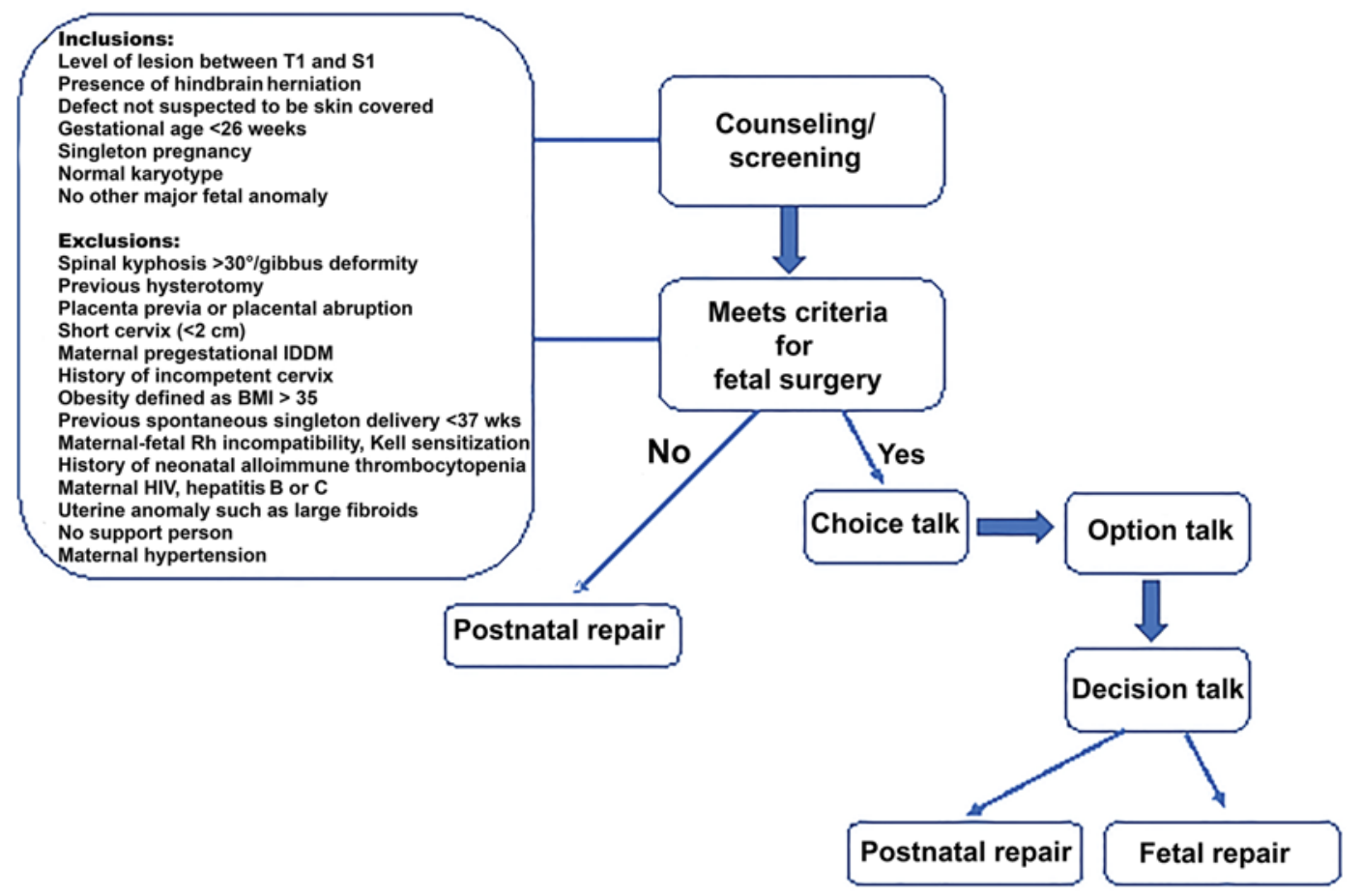

\section{"What matters most" initial preferences}

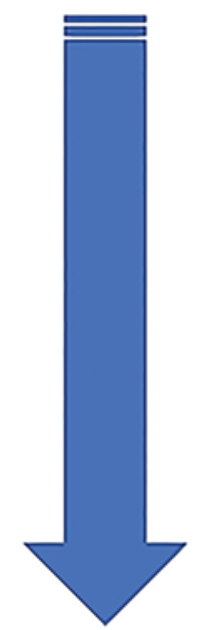

"What matters most" informed preferences

FIG. 1. Shared decision-making model for MMC. IDDM = insulin-dependent diabetes mellitus; $R h=$ Rhesus. Figure is available in color online only.

poorest candidates, because the chances of benefit are so low, have enlarged ventricles, significant paraplegia, and clubbed feet at the time of evaluation.

\section{Risk of Fetal MMC Repair}

The risks of fetal surgery are significant. There is a risk of fetal or infant death (2\%-6\%), and although it has never been reported, maternal death could occur. ${ }^{1,21,37,38}$ With fetal surgery, there is an increase in preterm birth (34.1 vs 37.3 weeks, $p<0.001$ ), and approximately $13 \%$ of patients are born before 30 weeks. ${ }^{1,43}$ Finally, an open hysterotomy can create significant complications for mother and child during the remainder of the pregnancy and in future pregnancies. There was an $10 \%$ incidence of uterine dehiscence in the MOMS, ${ }^{1}$ and recent reports have detailed significant complications in subsequent pregnancies as a result of open hysterotomy..$^{19}$ Additional maternal pregnancy risks include chorion-amnion membrane separation, spontaneous membrane rupture, oligohydramnios, placental abruption, and pulmonary edema. Newer minimally invasive techniques to improve maternal outcomes and lower pregnancy complications, such as mini-hysterotomy and fetoscopy, remain experimental. ${ }^{4-6}$

\section{Significant Maternal Commitment and Sacrifice in Fetal Surgery}

Undergoing fetal surgery requires significant lifestyle changes for the duration of the pregnancy. Many women must relocate nearer to a fetal care center and must submit to significant inconveniences, including bed rest, which can place additional stress on family and caregivers. ${ }^{1,25,28 \text {, }}$ 58,61 Additional considerations can include unemployment during this time and reduction of care of other children.
Given these demands and the potential for intensive monitoring during the antepartum period, these women must have robust support. If the expectant mother is a candidate for fetal surgery but lacks the resources or the desire to meet these requirements, fetal surgery is not a good option because of the complications that can ensue.

\section{Shared Decision-Making Model}

Shared decision-making depends on building a good relationship so that patients are supported and encouraged to deliberate and express their views during the decisionmaking process. ${ }^{16}$ It is broadly defined as "an approach where clinicians and patients share the best available evidence when faced with the task of making decisions, and where patients are supported to consider options, to achieve informed preferences."17 Three steps characterize a shared decision-making model: 1) introducing choice, 2) describing options, and 3 ) helping patients explore preferences and make decisions (Fig. 1). ${ }^{17}$ The model is derived from the notion that decisions should be made by considering the question of "what matters most," which carries different definitions for different families.

In the setting of MMC, mothers must understand that they have choices. Termination, postnatal closure, or fetal surgery may all be options. If the mother and fetus meet the criteria set forth, ${ }^{1}$ then counseling the mother on all options is necessary. However, mothers should not feel obligated to choose fetal surgery in order to "do everything they can for the child." Fetal surgery can have poor outcomes. The risk of death must be honestly discussed. If what matters most is safety, then postnatal closure of the 
MMC remains the best option. We recently reviewed our experience with the prenatal counseling of 175 referrals for MMC; 80 (46\%) patients qualified for repair, and of these, $57(71 \%)$ went on to have fetal surgery. ${ }^{42}$

If the decision is made to have fetal surgery, a final meeting before surgery with all surgical care providers helps ensure that all questions are answered and that there are no misunderstandings about the potential outcomes and risks. At our institution, the meeting occurs 24-72 hours before surgery.

\section{Conclusions}

Counseling expectant mothers requires a thorough knowledge of MMC and the treatment options. Pediatric neurosurgeons play an important role in the process. Multiple legitimate treatment options exist, but choosing the best option is difficult because of the many variables. The shared decision-making model provides a framework to help expectant mothers choose the treatment option best for them.

\section{References}

1. Adzick NS, Thom EA, Spong CY, Brock JW III, Burrows PK, Johnson MP, et al: A randomized trial of prenatal versus postnatal repair of myelomeningocele. N Engl J Med 364:993-1004, 2011

2. Antiel RM, Flake AW, Collura CA, Johnson MP, Rintoul NE, Lantos JD, et al: Weighing the social and ethical considerations of maternal-fetal surgery. Pediatrics 140:e20170608, 2017

3. Barf HA, Verhoef M, Jennekens-Schinkel A, Post MW, Gooskens RH, Prevo AJ: Cognitive status of young adults with spina bifida. Dev Med Child Neurol 45:813-820, 2003

4. Belfort MA, Whitehead WE, Shamshirsaz AA, Bateni ZH, Olutoye OO, Olutoye OA, et al: Fetoscopic open neural tube defect repair: development and refinement of a two-port, carbon dioxide insufflation technique. Obstet Gynecol 129:734-743, 2017

5. Belfort MA, Whitehead WE, Shamshirsaz AA, Ruano R, Cass DL, Olutoye OO: Fetoscopic repair of meningomyelocele. Obstet Gynecol 126:881-884, 2015

6. Botelho RD, Imada V, Rodrigues da Costa KJ, Watanabe LC, Rossi Júnior R, De Salles AAF, et al: Fetal myelomeningocele repair through a mini-hysterotomy. Fetal Diagn Ther 42:28-34, 2017

7. Bowman RM, McLone DG, Grant JA, Tomita T, Ito JA: Spina bifida outcome: a 25 -year prospective. Pediatr Neurosurg 34:114-120, 2001

8. Brock JW III, Carr MC, Adzick NS, Burrows PK, Thomas JC, Thom EA, et al: Bladder function after fetal surgery for myelomeningocele. Pediatrics 136:e906-e913, 2015

9. Bruinings AL, van den Berg-Emons HJ, Buffart LM, van der Heijden-Maessen HC, Roebroeck ME, Stam HJ: Energy cost and physical strain of daily activities in adolescents and young adults with myelomeningocele. Dev Med Child Neurol 49:672-677, 2007

10. Caldarelli M, Di Rocco C, La Marca F: Shunt complications in the first postoperative year in children with meningomyelocele. Childs Nerv Syst 12:748-754, 1996

11. Chakraborty A, Crimmins D, Hayward R, Thompson D: Toward reducing shunt placement rates in patients with myelomeningocele. J Neurosurg Pediatr 1:361-365, 2008

12. Danzer E, Adzick NS, Rintoul NE, Zarnow DM, Schwartz ES, Melchionni J, et al: Intradural inclusion cysts following in utero closure of myelomeningocele: clinical implications and follow-up findings. J Neurosurg Pediatr 2:406-413, 2008

13. Davis BE, Daley CM, Shurtleff DB, Duguay S, Seidel K, Loeser JD, et al: Long-term survival of individuals with myelomeningocele. Pediatr Neurosurg 41:186-191, 2005

14. Dias MS: Neurosurgical causes of scoliosis in patients with myelomeningocele: an evidence-based literature review. J Neurosurg 103 (1 Suppl):24-35, 2005

15. Eckstein HB, Cooper DG, Howard ER, Pike J: Cause of death in children with meningomyelocele or hydrocephalus. Arch Dis Child 42:163-165, 1967

16. Elwyn G, Frosch D, Thomson R, Joseph-Williams N, Lloyd A, Kinnersley P, et al: Shared decision making: a model for clinical practice. J Gen Intern Med 27:1361-1367, 2012

17. Elwyn G, Laitner S, Coulter A, Walker E, Watson P, Thomson R: Implementing shared decision making in the NHS. BMJ 341:c5146, 2010

18. Eng C, Iglehart D: Decision aids from genetics to treatment of breast cancer: long-term clinical utility or temporary solution? JAMA 292:496-498, 2004

19. Goodnight WH, Bahtiyar O, Bennett KA, Emery SP, Lillegard JB, Fisher A, et al: Subsequent pregnancy outcomes after open maternal-fetal surgery for myelomeningocele. Am J Obstet Gynecol 220:494.e1-494.e7, 2019

20. Hall JG, Solehdin K: Genetics of neural tube defects. Ment Retard Dev Disabil Res Rev 4:269-281, 1998

21. Heuer GG, Adzick NS, Sutton LN: Fetal myelomeningocele closure: technical considerations. Fetal Diagn Ther 37:166171,2015

22. Hudgins RJ, Gilreath CL: Tethered spinal cord following repair of myelomeningocele. Neurosurg Focus 16(2):E7, 2004

23. Hunt GM: 'The median survival time in open spina bifida.' Dev Med Child Neurol 39:568, 1997 (Letter)

24. Hunt GM: Open spina bifida: outcome for a complete cohort treated unselectively and followed into adulthood. Dev Med Child Neurol 32:108-118, 1990

25. Johnson MP, Bennett KA, Rand L, Burrows PK, Thom EA, Howell LJ, et al: The Management of Myelomeningocele Study: obstetrical outcomes and risk factors for obstetrical complications following prenatal surgery. Am J Obstet Gynecol 215:778.e1-778.e9, 2016

26. Kessler TM, Lackner J, Kiss G, Rehder P, Madersbacher H: Predictive value of initial urodynamic pattern on urinary continence in patients with myelomeningocele. Neurourol Urodyn 25:361-367, 2006

27. Kulkarni AV, Schiff SJ, Mbabazi-Kabachelor E, Mugamba J, Ssenyonga P, Donnelly R, et al: Endoscopic treatment versus shunting for infant hydrocephalus in Uganda. N Engl J Med 377:2456-2464, 2017

28. Lindemann H: Why families matter. Pediatrics 134 (Suppl 2):S97-S103, 2014

29. Lorber J: Spina bifida cystica. Results of treatment of 270 consecutive cases with criteria for selection for the future. Arch Dis Child 47:854-873, 1972

30. Luthy DA, Wardinsky T, Shurtleff DB, Hollenbach KA, Hickok DE, Nyberg DA, et al: Cesarean section before the onset of labor and subsequent motor function in infants with meningomyelocele diagnosed antenatally. $\mathbf{N}$ Engl J Med 324:662-666, 1991

31. Macedo A Jr, Ottoni SL, Garrone G, Liguori R, Cavalheiro $\mathrm{S}$, Moron A, et al: In utero myelomeningocoele repair and urological outcomes: the first 100 cases of a prospective analysis. Is there an improvement in bladder function? BJU Int 123:676-681, 2019

32. Maroto A, Illescas T, Meléndez M, Arévalo S, Rodó C, Peiró JL, et al: Ultrasound functional evaluation of fetuses with myelomeningocele: study of the interpretation of results. J Matern Fetal Neonatal Med 30:2301-2305, 2017

33. Mazur DJ, Hickam DH, Mazur MD, Mazur MD: The role of 
doctor's opinion in shared decision making: what does shared decision making really mean when considering invasive medical procedures? Health Expect 8:97-102, 2005

34. McDonald CM, Jaffe KM, Mosca VS, Shurtleff DB: Ambulatory outcome of children with myelomeningocele: effect of lower-extremity muscle strength. Dev Med Child Neurol 33:482-490, 1991

35. McLone DG, Dias MS: The Chiari II malformation: cause and impact. Childs Nerv Syst 19:540-550, 2003

36. McLone DG, Knepper PA: The cause of Chiari II malformation: a unified theory. Pediatr Neurosci 15:1-12, 1989

37. Moldenhauer JS, Adzick NS: Fetal surgery for myelomeningocele: After the Management of Myelomeningocele Study (MOMS). Semin Fetal Neonatal Med 22:360-366, 2017

38. Moldenhauer JS, Soni S, Rintoul NE, Spinner SS, Khalek N, Martinez-Poyer J, et al: Fetal myelomeningocele repair: the post-MOMS experience at the Children's Hospital of Philadelphia. Fetal Diagn Ther 37:235-240, 2015

39. National Institute of Neurological Disorders and Stroke: Spina bifida fact sheet. NINDS/NIH (https://www.ninds. nih.gov/Disorders/Patient-Caregiver-Education/Fact-Sheets/ Spina-Bifida-Fact-Sheet) [Accessed January 3, 2020]

40. Oakeshott P, Hunt GM: Long-term outcome in open spina bifida. Br J Gen Pract 53:632-636, 2003

41. O'Hayon BB, Drake JM, Ossip MG, Tuli S, Clarke M: Frontal and occipital horn ratio: a linear estimate of ventricular size for multiple imaging modalities in pediatric hydrocephalus. Pediatr Neurosurg 29:245-249, 1998

42. Pan ET, Pallapati J, Krueger A, Yepez M, VanLoh S, Nassr AA, et al: Evaluation and disposition of fetal myelomeningocele repair candidates: a large referral center experience. Fetal Diagn Ther 47:115-122, 2020

43. Parker SE, Mai CT, Canfield MA, Rickard R, Wang Y, Meyer RE, et al: Updated national birth prevalence estimates for selected birth defects in the United States, 2004-2006. Birth Defects Res A Clin Mol Teratol 88:1008-1016, 2010

44. Rintoul NE, Sutton LN, Hubbard AM, Cohen B, Melchionni J, Pasquariello PS, et al: A new look at myelomeningoceles: functional level, vertebral level, shunting, and the implications for fetal intervention. Pediatrics 109:409-413, 2002

45. Riva-Cambrin J, Kestle JRW, Rozzelle CJ, Naftel RP, Alvey JS, Reeder RW, et al: Predictors of success for combined endoscopic third ventriculostomy and choroid plexus cauterization in a North American setting: a Hydrocephalus Clinical Research Network study. J Neurosurg Pediatr 24:128-138, 2019

46. Seitzberg A, Lind M, Biering-Sørensen F: Ambulation in adults with myelomeningocele. Is it possible to predict the level of ambulation in early life? Childs Nerv Syst 24:231237, 2008

47. Sheridan SL, Harris RP, Woolf SH: Shared decision making about screening and chemoprevention. A suggested approach from the U.S. Preventive Services Task Force. Am J Prev Med 26:56-66, 2004

48. Singhal B, Mathew KM: Factors affecting mortality and morbidity in adult spina bifida. Eur J Pediatr Surg 9 (Suppl 1):31-32, 1999

49. Steinbok P, Irvine B, Cochrane DD, Irwin BJ: Long-term outcome and complications of children born with meningomyelocele. Childs Nerv Syst 8:92-96, 1992

50. Stevenson KL: Chiari Type II malformation: past, present, and future. Neurosurg Focus 16(2):E5, 2004

51. Thompson DN: Postnatal management and outcome for neural tube defects including spina bifida and encephalocoeles. Prenat Diagn 29:412-419, 2009
52. Toriello HV, Higgins JV: Possible causal heterogeneity in spina bifida cystica. Am J Med Genet 21:13-20, 1985

53. Tuli S, Drake J, Lamberti-Pasculli M: Long-term outcome of hydrocephalus management in myelomeningoceles. Childs Nerv Syst 19:286-291, 2003

54. Tuli S, Tuli J, Drake J, Spears J: Predictors of death in pediatric patients requiring cerebrospinal fluid shunts. J Neurosurg 100 (5 Suppl Pediatrics):442-446, 2004

55. Tulipan N, Wellons JC III, Thom EA, Gupta N, Sutton LN, Burrows PK, et al: Prenatal surgery for myelomeningocele and the need for cerebrospinal fluid shunt placement. J Neurosurg Pediatr 16:613-620, 2015

56. Valtonen K, Karlsson AK, Alaranta H, Viikari-Juntura E: Work participation among persons with traumatic spinal cord injury and meningomyelocele. J Rehabil Med 38:192-200, 2006

57. van Roosmalen MS, Stalmeier PF, Verhoef LC, HoekstraWeebers JE, Oosterwijk JC, Hoogerbrugge N, et al: Randomized trial of a shared decision-making intervention consisting of trade-offs and individualized treatment information for BRCA1/2 mutation carriers. J Clin Oncol 22:3293-3301, 2004

58. Verkerk MA, Lindemann H, McLaughlin J, Scully JL, Kihlbom U, Nelson J, et al: Where families and healthcare meet. J Med Ethics 41:183-185, 2015

59. Warf BC: Comparison of endoscopic third ventriculostomy alone and combined with choroid plexus cauterization in infants younger than 1 year of age: a prospective study in 550 African children. J Neurosurg 103 (6 Suppl):475-481, 2005

60. Warf BC, Campbell JW: Combined endoscopic third ventriculostomy and choroid plexus cauterization as primary treatment of hydrocephalus for infants with myelomeningocele: long-term results of a prospective intent-to-treat study in 115 East African infants. J Neurosurg Pediatr 2:310-316, 2008

61. Wilson RD, Lemerand K, Johnson MP, Flake AW, Bebbington M, Hedrick HL, et al: Reproductive outcomes in subsequent pregnancies after a pregnancy complicated by open maternal-fetal surgery (1996-2007). Am J Obstet Gynecol 203:209.e1-209.e6, 2010

62. Woodhouse CR: Myelomeningocele: neglected aspects. Pediatr Nephrol 23:1223-1231, 2008

63. Yamada S, Won DJ, Yamada SM: Pathophysiology of tethered cord syndrome: correlation with symptomatology. Neurosurg Focus 16(2):E6, 2004

\section{Disclosures}

The authors report no conflict of interest concerning the materials or methods used in this study or the findings specified in this paper.

\section{Author Contributions}

Conception and design: Whitehead. Drafting the article: Whitehead, Ravindra. Critically revising the article: all authors.

Reviewed submitted version of manuscript: all authors. Approved the final version of the manuscript on behalf of all authors: Whitehead.

\section{Correspondence}

William E. Whitehead: Texas Children's Hospital, Houston, TX. wewhiteh@texaschildrens.org. 